University of Zurich

Department of Economics

Working Paper Series

ISSN 1664-7041 (print)

ISSN 1664-705X (online)

Working Paper No. 71

\title{
Designing Package Markets to Eliminate Exposure Risk
}

Jacob K. Goeree and Luke Lindsay

April 2012 


\title{
Designing PaCkage Markets to Eliminate Exposure Risk
}

\author{
Jacob K. Goeree and Luke Lindsay*
}

April 16, 2012

\begin{abstract}
This paper reports results from a series of laboratory experiments designed to evaluate the impact of exposure risk on market performance. Exposure risk arises when there are complementarities between trades, e.g. when the purchase of a new house requires selling the old one. The continuous double auction (CDA), which has proven to be remarkably effective in a wide variety of settings, performs poorly in a treatment with high exposure risk: overall market efficiency is only $20 \%$ and there are many instances of no trade. In a parallel treatment with lower exposure risk, efficiency under the CDA is higher (55\%) but is dominated, for instance, by a top-trading-cycles procedure that uses no money. The CDA's poor performance does not depend on whether house values are private information or common knowledge, indicating that exposure risk is due to strategic uncertainty not objective uncertainty about others' preferences. We introduce a simple package market and show that it effectively resolves exposure risk: efficiency levels are $82 \%$ and $89 \%$ respectively for the low and high exposure treatments. The proposed package market is a simple extension of the CDA and could potentially be applied in a variety contexts.
\end{abstract}

Keywords: Exposure risk, package markets, market design, laboratory experiments

${ }^{*}$ Chair for Organizational Design, Department of Economics, University of Zürich, Blümlisalpstrasse 10, CH-8006, Zürich, Switzerland. We would like to thank the Swiss National Science Foundation (SNSF 138162) and the European Research Council (ERC Advanced Investigator Grant, ESEI-249433) for financial support. We are grateful for the many useful comments and suggestions we received from seminar participants at Carlos III in Madrid, Bocconi University, the Max Plack Institute in Bonn, Nottingham University, University of Luxembourg, the ESA Meetings in Luxembourg and Chicago, the "Experimental Finance" conference in Innsbruck, and the "Experiments in Auction and Market Design" workshop in Sydney. 


\section{Introduction}

Undoubtedly the most celebrated success story of experimental economics is Vernon Smith's (1962) finding that behavior in continuous double auction (CDA) markets robustly converges to competitive equilibrium outcomes. This finding is remarkable and striking in that convergence occurs when it is not predicted. The experiments employ only a small number of buyer and sellers, there is no common knowledge of demand and supply, and subjects are not price takers but rather price makers. As Smith (1982) notes, the predictive ability of competitive equilibrium is a "scientific mystery" that poses a challenge to game theoretic modeling? The mystery has been replicated hundreds of times, across a wide variety of subject pools and market environments (Smith, 2010).

The experimental results reported in this paper form somewhat of an opposite mystery. We consider a simple setting with four subjects who each own a house and who each have values for all four houses. When subjects' values are common knowledge, the possible gains from trade are apparent and the Coase theorem applies. Nevertheless, observed efficiency levels in the CDA are very low with many instances of no trade. While this poor performance contrasts with that of previous studies, it has an intuitive explanation that forms the basis for our experimental design $\sqrt{2}^{2}$ In our setup, houses are substitutes, which results in complementarities between trades. When a subject buys a new house she may need to sell her old house in order not to be worse off. A buyer risks being financially exposed when a subsequent sell transaction is not guaranteed, e.g. when there is strategic uncertainty about others' bargaining behavior. Anticipating such exposure risk and the potential for a loss, subjects may not be willing to buy, resulting in low market efficiency or even no trade.

To quantify the effects of exposure risk, we compare market performance in two parallel treatments. In the low-exposure treatment, all house values are shifted downward by a common constant compared to the values used in the high-exposure treatment. As a result, the total gains from trade are the same but the risk associated with buying a second house is less. We find that this manipulation has a strong positive effect. Efficiency levels are significantly and substantially higher in the low-exposure treatment, providing evidence for the impact of

\footnotetext{
${ }^{1}$ See, however, Friedman (2010) for a more up-to-date and positive outlook on game theoretic modeling of behavior in the CDA.

${ }^{2}$ Another exception where the CDA performs poorly is when there are avoidable costs in production. These are costs that are not incurred if the activity is suspended (unlike fixed costs). Avoidable costs may cause non-existence of competitive equilibrium with adverse consequences for efficiency and stability. Van Boening and Wilcox (1996) find that the CDA fails in the presence of avoidable costs with observed efficiencies of $50 \%$ or less and highly erratic price dynamics. In this paper we consider a much simpler exchange economy without production for which the competitive equilibrium always exists.
} 
exposure risk on market performance.

To put the CDA's poor performance in perspective, we simulate efficiency numbers for a top-trading-cycles mechanism without money. In this mechanism, subjects would simply point to the house they prefer most among those available. The mechanism proceeds in several steps, where in each step the houses (and owners) that form cycles are removed ${ }^{3}$ Without money this simple procedure obviously cannot be fully efficient but it does outperform the CDA in both the low and high-exposure treatments.

Our proposed solution is a simple extension of the CDA. It is a package market, which, like the CDA, allows for standard buy and sell offers involving a single house and some amount of cash. In addition, it allows for offers in which one house is offered, one is demanded, plus some amount of cash is offered or demanded. Such "package offers" allow subjects to exchange houses without running the risk of ending up with two houses or none at all. And, unlike in the top-trading-cycles procedure, such exchanges may involve money as well. We find that the package market effectively solves the problem of exposure risk: efficiency levels are high and significantly above those observed in the CDA and the top-trading-cycles procedure.

Since the proposed package market is a simple adaptation of the CDA, it could potentially be applied in a variety contexts. Besides real-estate markets one could think of markets for other expensive durables such as cars, boats, etc. Another obvious candidate is financial markets where "swaps," i.e. package orders that do not involve money, are often introduced to mitigate exposure risk. A different application concerns the trading of NBA basketball players. Whether a team wants to sell a certain player will often depend on whether they can find a suitable replacement. In such cases, package orders could facilitate trade especially when multiple players and teams are involved.

Another example is the reallocation of airport resources in bad weather. As described by Balakrishnan (2007), the number of take-off and landing slots at airports are limited and adverse weather conditions such as thunderstorms decrease the airport's capacity further. This may result in carriers being unable to use slots allocated to them and cause a surge in demand at later times. Short surges can be dealt with using an airborne control procedure like hold patterns and longer ones can be dealt with by delaying flights at departure airports. These measures are costly, however. Costs could be reduced when slots are efficiently traded in a package market that is able to ensure each carrier is assigned exactly one slot.

A final example concerns the reallocation of licenses to use radio spectrum. Such licenses have been auctioned off by the US government since 1994. Over time, demand for services that

\footnotetext{
${ }^{3}$ This cycle may consist of only a single owner pointing to her own house.
} 
rely on radio spectrum have changed and the technology to exploit spectrum has improved, e.g. digital television requires much less bandwidth than analogue transmission. Furthermore, telecom operators that successfully participated in different spectrum auctions now typically own licenses that are dispersed both in the geographic and frequency domains. Since geographically adjacent, contiguous blocks of spectrum are more valuable there are likely gains from trade. A package market could facilitate a more efficient allocation of licenses while ensuring telecom operators that their overall network capacity remains intact.

\subsection{Related Literature}

In recent years there has been a considerable amount of research on package auctions but research on package exchanges is less developed, see, for instance, Milgrom (2007) for an excellent account of the current state of the literature. One approach to package market design is extending existing package auction formats (e.g. one seller and multiple buyers) to the two-sided case with multiple buyers and sellers. For instance, Lubin et al. (2008) develop a package exchange built around the combinatorial ascending auction. The allocation and prices are determined iteratively with traders revising their orders at each step.

Another approach is a direct mechanism or call market where participants submit orders once, and after a predetermined time the allocation and prices are determined. Bossaerts, Fine, and Ledyard (2002) suggest an exchange of this form for trading securities when investors are interested in holding certain portfolios. Allowing traders to submit package orders protects against being left holding an unbalanced portfolio, which might otherwise occur when the markets are thin. Milgrom (2009) proposes a generalized message space - the space of assignment messages - for use in exchanges and other direct mechanisms where goods are substitutes. Our approach is somewhat different in that we extend a standard (non-package) market mechanism, the continuous double auction, to accommodate package orders.

\subsection{Organization}

This paper is organized as follows. Section 2 describes the trading environment and provides intuition for why exposure risk may hamper market performance. In Section 3 we provide a detailed account of both market institutions, i.e. the simple continuous double auction market and its package variant. The experimental design is explained in Section 4. We next provide results on market efficiency (Section 5.1), the impact of exposure risk (Section 5.2), and the top-trading-cycles (Section 5.3). Section 6 concludes. A screen shot of the interface subjects used and the instructions can be found in the (online) Appendix. 


\section{The Environment}

A variant of the assignment game presented by Shapley and Shubik (1971) captures the essence of our setup $4^{4}$ Indivisible items, houses, are traded for money. Each agent demands exactly one house. There are $N$ agents, the set of agents is represented by $I=\{1, \ldots, N\}$. Each agent has a house, the set of $N$ houses is represented by $H=\{1, \ldots, N\}$. Agent $i$ is initially endowed with house $i$. Each agent has a private value for each of the houses, $v_{i}^{h} \sim U[\underline{v}, \bar{v}]$ where $0 \leq \underline{v}<\bar{v}$. Agent $i$ 's quasi-linear utility is $c_{i}+\max \left(v_{i}^{1} \omega_{i}^{1}, \ldots, v_{i}^{N} \omega_{i}^{N}\right)$, where $c_{i}$ is the quantity of money held by agent $i$ and $\omega_{i}^{h}$ is one if the agent holds house $h$ and zero otherwise. Let $\Omega=\left\{\omega_{1}, \ldots, \omega_{N}\right\}$ and $\Omega^{*}$ be the allocation of houses to agents that maximizes overall surplus. For this simple exchange economy there typically exists a continuum of competitive prices $p^{*}$ that support this allocation.5

An example with four agents is shown in Table 1. The numbers in the table represent agents' values for each of the houses. The underlined values indicate which house each agent is initially endowed with while the starred values indicate the allocation that maximizes surplus. It is readily verified that $\left(p_{A}=0, p_{B}=1, p_{C}=11, p_{D}=0\right)$ are competitive prices and so are, for instance, $\left(p_{A}=52, p_{B}=58, p_{C}=63, p_{D}=54\right)$.

\subsection{The Exposure Problem with Substitutes}

Despite the existence of competitive prices, the exposure problem may prevent the optimal allocation from being realized. In our model, houses are substitutes in the sense that for agent $i$, the value of owning houses $A$ and $B$ together is less than or equal to the sum of the value of owning house $A$ alone and the value of owning house $B$ alone. That is, $\max \left(v_{i}^{A}, v_{i}^{B}\right) \leq v_{i}^{A}+v_{i}^{B}$ since values are non-negative. Suppose $v_{i}^{h} \sim U[10,15]$ and consider the trade where agent $i$ buys agent $j$ 's house for an amount of cash $b$. Agent $i$ now holds houses $i$ and $j$; agent $j$ now holds an amount $b$ of extra cash. Agent $i$ 's gain from trade is $\pi_{i}=\max \left(v_{i}^{j}, v_{i}^{i}\right)-b-v_{i}^{i}$ and agent $j$ 's gain is $\pi_{j}=b-v_{j}^{j}$. Hence, the total gain is $\pi_{i}+\pi_{j}=\max \left(v_{i}^{j}, v_{i}^{i}\right)-v_{j}^{j}-v_{i}^{i}$. Given the distribution of draws, $\max \left(v_{i}^{j}, v_{i}^{i}\right)-v_{i}^{i} \leq 5$ and $-v_{j}^{j} \leq-10$ so $\pi_{i}+\pi_{j} \leq-5$. This means that at least one agent must make a loss on the first trade. If there is uncertainty about whether the loss can be recouped in later trades, then trade may not occur. This problem is exacerbated by the fact that after the first trade the buyer has two houses, but his marginal value for the less preferred house is zero, which weakens his bargaining position. As a consequence, there

\footnotetext{
${ }^{4}$ Shapley and Shubik (1971) consider the case of $m$ sellers and $n$ buyers. Only sellers are initially endowed with an item. The buyers value all items while the sellers value only the item they are initially endowed with.

${ }^{5}$ The set of competitive equilibrium prices form a bounded lattice, see also Shapley and Shubik (1971).
} 


\begin{tabular}{|c|c|c|c|c|}
\hline & Agent 1 & Agent 2 & Agent 3 & Agent 4 \\
\hline \hline House A & $\underline{40}$ & $55^{*}$ & 65 & 50 \\
\hline House B & 50 & $\underline{35}$ & $75^{*}$ & 55 \\
\hline House C & $63^{*}$ & 66 & $\underline{52}$ & 62 \\
\hline House D & 45 & 44 & 71 & $\underline{54^{*}}$ \\
\hline
\end{tabular}

Table 1: Example with four agents and four houses. The underlined values correspond to the initial allocation and the starred values to the optimal allocation.

is a reason for agents to wait for others to make the first trade, which could lead to no trade occurring.

\section{Market Institutions}

We evaluate two institutions: a simple CDA market and a package market. In both markets, traders submit orders in continuous time and trade occurs instantly when a set of compatible orders has accumulated. The markets differ in the types of order that are admissible. In the simple market, buy and sell orders are allowed; in the package market, buy, sell, and package orders are allowed.

The following framework is used to describe traders' orders and holdings. An order is a pair $o=(b, x)$ where $b$ is a real number representing the amount of cash being offered or requested and $x \in\{-1,0,1\}^{N}$ is a vector indicating which houses offered or demanded. Positive values indicate an item is demanded and negative values indicate that it is offered. For example $(-20,\langle 0,1,0,0\rangle)$ indicates "I am willing to pay up to 20 for house B" and $(30,\langle-1,0,0,0\rangle)$ indicates "I am willing to accept 30 or more for house A." Orders are submitted in continuous time. An order is active until it transacts or is withdrawn. Let $O^{t}$ denote active orders at time $t$ and let $O_{i}^{t}$ denote the active orders submitted by trader $i$. Elements of $O^{t}$ are denoted $o_{j}=\left(b_{j}, x_{j}\right)$. Let $\omega_{i} \in\{0,1\}^{N}$ denote the houses held by trader $i$ and $c_{i}$ the amount of cash held by trader $i$.

In the simple market, two types of order are allowed: buying orders $(b<0$ and exactly one component of $x$ is 1 and the rest are zero) and selling orders ( $b>0$ and exactly one component of $x$ is -1 and the rest are zero). In the package market, package orders are allowed in addition to buying and selling orders. In a package order, at least one component of $x$ is 1 , at least one component of $x$ is -1 , and $b$ can take any value.

Each time a new order is submitted, an algorithm is run that determines if any transactions 
will occur. The winning orders (and hence the houses that get reallocated) are selected by maximizing the cash surplus. The cash surplus is calculated using the quantities traders specify in their orders. (Note that since the cash surplus depends on submitted orders rather than preferences, it need not correspond to the economic surplus.) Let $d_{j}=1$ if order $j$ is winning and $d_{j}=0$ otherwise. The vector $d$ is found by solving the following:

$$
\begin{aligned}
& \max _{d} \sum_{j \in O^{t}}-b_{j} d_{j} \\
& \text { subject to } \\
& \text { indivisibility: } d_{j} \in\{0,1\} \text { for all } j \in O^{t} \\
& \text { supply equals demand: } \sum_{j \in O^{t}} x_{j}^{k} d_{j}=0 \text { for all } k \in H \\
& \text { no short selling: } \omega_{i}^{k}+\sum_{j \in O_{i}^{t}} x_{j}^{k} d_{j} \geq 0 \text { for all } k \in H, i \in I \\
& \text { budget constraints: } c_{i}+\sum_{j \in O_{i}^{t}} b_{j}^{k} d_{j} \geq 0 \text { for all } i \in I
\end{aligned}
$$

Let the set of winning orders be denoted $W=\left\{j \in O^{t} \mid d_{j}=1\right\}$ and the set of losing orders $L=O^{t} \backslash W$. For losing orders, the submitter does not pay or receive anything. For winning orders, the submitter receives or pays an amount of cash $y_{j} \geq b_{j}$. In cases where $\sum_{j \in W}-b_{j}=0$, the total amount of cash offered exactly matches the amount requested, so $y_{j}=b_{j}$. In cases where $\sum_{j \in W}-b_{j}>0$, there is a cash surplus. No revenue is extracted, the entire cash surplus is redistributed. This means that for some $j \in W, y_{j}>b_{j}$. To determine the division of this cash surplus, a vector of prices $p$ is chosen that solves the following: ${ }^{6}$

$$
\begin{aligned}
& p \cdot x_{j}+b_{j} \leq 0 \text { for all } j \in W \\
& p \cdot x_{j}+b_{j} \geq 0 \text { for all } j \in L
\end{aligned}
$$

Once prices have been chosen, the payment for order $j$ is $p \cdot x_{j}$.

An example of how the algorithm operates in the simple market is shown in the left panel of Table 2. The columns headings use the variables defined above. Each row in the table represents an order. Order 1 is offering to sell house $A$ for 20 . Order 2 offers to buy house $A$ for 30 and order 3 offers to buy it for 27. The cash surplus is maximized if orders 1 and 2 are

\footnotetext{
${ }^{6}$ Since the solution is not necessarily unique, a way to choose between alternatives is needed. The approach used is to lexicographically maximize the minimum surplus $y_{j}-b_{j}$, see Kwasnica et al. (2005).
} 


\begin{tabular}{|c|c|c|c|c|}
\hline$j$ & $b$ & $x$ & $d$ & $y$ \\
\hline \hline 1 & 20 & $\langle-1,0,0,0\rangle$ & 1 & 27 \\
\hline 2 & -30 & $\langle 1,0,0,0\rangle$ & 1 & -27 \\
\hline 3 & -27 & $\langle 1,0,0,0\rangle$ & 0 & \\
\hline
\end{tabular}

\begin{tabular}{|c|c|c|c|c|}
\hline$j$ & $b$ & $x$ & $d$ & $y$ \\
\hline \hline 1 & 0 & $\langle-1,0,1,0\rangle$ & 1 & 2 \\
\hline 2 & 0 & $\langle 1,-1,0,0\rangle$ & 1 & 2 \\
\hline 3 & -6 & $\langle 0,1,-1,0\rangle$ & 1 & -4 \\
\hline
\end{tabular}

Table 2: Examples of orders and transactions in the simple market (left) and package market (right).

winning. A price for house $A$ of 27 maximizes the minimum surplus subject to the constraint that supply equals demand.

The right panel of the Table 2 shows an example for the package market. Order 1 offers to trade house $A$ for house $C$ without any money changing hands (a "swap"). Likewise, order 2 offers to swap house $B$ for house $A$. Finally, order 3 offers to trade $C$ for house $B$ and pay six in cash. All three orders are winning and the six units of cash surplus are distributed evenly. Note that even though all orders offer to trade one house for another more than two orders may be involved in a transaction, e.g. in this example the winning orders form a "three cycle."

\section{Experimental Design}

The experiment used a instance of the problem described in Section 2. The instructions for the experiment were read out loud to the subjects using a short PowerPoint presentation. We chose this format to ensure common knowledge and to let us explain the user interface of the experimental software in detail. Subjects were assigned to groups of four people that were fixed for the entire experiment. In each period, subjects were endowed with a house and 100 cash. There were three unpaid practice periods followed by 15 paid periods each of which lasted three minutes.7.$^{7}$ Subjects received new private value draws and endowments at the start of each period. During a period there was no limit on how many orders a subject could submit 8

There were eight treatments and each subject participated in one treatment. There were six groups per treatment. A factorial design with the following three factors was used. First, a simple market was compared to a package market. Second, a high exposure environment was compared to a low exposure environment. In the low exposure environment, house values were drawn uniformly from $[0,50]$. In the high exposure setting, the draws were generated by adding 25 to the draws from the low exposure treatment. Varying the degree of exposure

\footnotetext{
${ }^{7}$ In a pilot session longer period times were tried. These produced similar results but subjects commented that the experiment was too slow.

${ }^{8} \mathrm{~A}$ screenshot of the software subjects used can be found in the Appendix. The slides for the instructions are included as a supplementary file.
} 
lets us determine whether differences in market performance were caused by exposure or other factors. Third, a complete information environment where subjects' values for the four houses were public information was compared to a incomplete information environment where subject only knew their own values (and who owned what house). Varying this information lets us determine whether the exposure problem was caused by uncertainty about others' values or other factors such as strategic uncertainty and hold-out.

A total of 192 subjects took part in the experiment. Subjects were paid based on the realized gains from trade, i.e. for each subject in each period, earnings were calculated as $u$ (final holdings $)-u$ (endowment). The resulting values for each of the 15 periods were summed giving a total number of points earned in the experiment. Subjects were paid 0.2 Swiss Francs for each point plus a 15 Franc show-up fee. Average earnings were 35 Swiss Francs and the experiment lasted 1.5 hours.

\section{Results}

In Section 5.1 we compare the two market institutions in terms of efficiency. We then discuss in detail how exposure risk affects the continuous double auction in Section 5.2. In Section 5.3 we compare the simple and package markets to the top-trading-cycles procedure.

\subsection{Market Performance}

First we focus on the proportion of the potential gains from trade that were realized in different treatments. Realized gains are calculated at the group level over the 15 periods:

$$
\text { realized gains }=\frac{\sum_{t=1}^{15} \pi_{t}-\underline{\pi}_{t}}{\sum_{t=1}^{15} \bar{\pi}_{t}-\underline{\pi}_{t}} \times 100 \%
$$

where $\pi_{t}$ is the total earnings of the four group members in period $t, \underline{\pi}_{t}$ is the total earnings if there had been no trade, and $\bar{\pi}_{t}$ is the total earnings if the maximum surplus had been obtained. The gains realized in the different treatments are shown in the first three columns of Table 3 (the other columns are discussed below). Changes in the market mechanism or the degree of exposure have a clear effect on the proportion of gains realized, but whether or not subjects had complete information has no apparent effect $?^{9}$

\footnotetext{
${ }^{9}$ For this reason, the complete and incomplete information treatments are pooled in the rest of the analysis.
} 


\begin{tabular}{|c|c|c|c||c|c|c|}
\hline & $\begin{array}{c}\text { Complete } \\
\text { Information }\end{array}$ & $\begin{array}{c}\text { Incomplete } \\
\text { Information }\end{array}$ & Pooled & $\begin{array}{c}\text { Buy } \\
\text { Orders }\end{array}$ & $\begin{array}{c}\text { Sell } \\
\text { Orders }\end{array}$ & $\begin{array}{c}\text { Package } \\
\text { Orders }\end{array}$ \\
\hline \hline Simple Low & $53.2 \%$ & $57.4 \%$ & $55.3 \%$ & $35.2 \%$ & $64.8 \%$ & $0.0 \%$ \\
\hline Simple High & $19.7 \%$ & $19.7 \%$ & $19.7 \%$ & $36.5 \%$ & $63.5 \%$ & $0.0 \%$ \\
\hline Package Low & $82.5 \%$ & $81.2 \%$ & $81.8 \%$ & $4.0 \%$ & $11.7 \%$ & $84.3 \%$ \\
\hline Package High & $90.8 \%$ & $87.1 \%$ & $88.9 \%$ & $2.7 \%$ & $4.3 \%$ & $93.0 \%$ \\
\hline
\end{tabular}

Table 3: The first three columns show realized gains by treatment. "Simple Low" refers to the simple market with low exposure, "Package High" to the package market with high exposure etc. The "Pooled" column shows averages of the "Complete Information" and "Incomplete Information" columns. The final three columns show the types of orders placed in the simple and package market under low/high exposure (with data from the complete and incomplete information treatments pooled).

Result 1: In the high exposure setting, 20 percent of the gains from trade are realized in the simple market and 89 percent in the package market.10 In the low exposure setting, 55 percent of the gains from trade are realized in the simple market and 82 percent in the package market 11 Switching between complete and incomplete information does not affect the realized gains from trade.

Three aspects of this result are remarkable. First, the low fraction of the gains from trade that are realized in the simple market. In other settings, the CDA often produces efficiency levels close to 100 percent. Second, the size of the effect of changing the market institution. In auction experiments, for example, different auction formats typically realize different proportions of the potential gains from trade. However, the differences are usually in the range of a few percentage points (e.g., Brunner et al., 2010). Third, the absence of a treatment effect when information about house values is made public. This indicates that observed inefficiencies are not due to information rents associated with private information but rather with strategic uncertainty about others' behavior.

One natural question is whether the package market performs better only in "difficult" cases where an exchange among three or four subjects is required to achieve the optimal allocation. Table 4 shows the fraction of the gains realized by the two market institutions for all possible scenarios. Here [2] indicates that going from the initial to the optimal allocation involves only a pair of subjects trading their houses. Similarly, $[2,2]$ means that two such pairs are needed while [3] and [4] indicate cases where three or four subjects are needed to complete the exchange. Finally, $[\emptyset]$ indicates that the initial allocation is already optimal.

\footnotetext{
${ }^{10}$ This difference is significant $(p<0.0001$, Mann-Whitney test).

${ }^{11}$ Also this difference is significant ( $p=0.0008$, Mann-Whitney test).
} 


\begin{tabular}{|c|c|c|c|c|c|}
\hline \multirow{2}{*}{$\begin{array}{c}\text { Optimal } \\
\text { Cycle }\end{array}$} & \multirow{2}{*}{ \# Obs } & \multicolumn{4}{|c|}{ Realized Gains } \\
\cline { 3 - 6 } & Simple Low & Simple High & Package Low & Package High \\
\hline \hline$[2]$ & 248 & $36.5 \%$ & $12.1 \%$ & $79.2 \%$ & $93.4 \%$ \\
\hline$[3]$ & 216 & $63.7 \%$ & $6.7 \%$ & $87.6 \%$ & $93.8 \%$ \\
\hline$[2,2]$ & 32 & $47.7 \%$ & $22.6 \%$ & $84.2 \%$ & $85.1 \%$ \\
\hline$[4]$ & 200 & $65.4 \%$ & $31.4 \%$ & $79.0 \%$ & $83.7 \%$ \\
\hline$[\emptyset]$ & 24 & $\mathrm{n} / \mathrm{a}$ & $\mathrm{n} / \mathrm{a}$ & $\mathrm{n} / \mathrm{a}$ & $\mathrm{n} / \mathrm{a}$ \\
\hline
\end{tabular}

Table 4: Realized gains in the simple and package market by complexity of the cycle that is needed to go from the initial to the optimal allocation.

Result 2: Market performance is unaffected by the type of exchange cycle required to go from the initial to the optimal allocation.

The columns labeled "Package Low" and "Package High" in Table 4 show that the package market realizes 80 to 90 percent of the total gains from trade irrespective of whether a bilateral or a more complex exchange is needed. The columns labeled "Simple Low" and "Simple High" suggest that efficiency of the CDA varies with the type of cycle required. To test this formally we run a simple linear regression of the form

$$
\text { realized gains } \text { g,t }=\beta_{0} d_{\text {high }}+\beta_{1} d[2]_{g, t}+\beta_{2} d[3]_{g, t}+\beta_{3} d[2,2]_{g, t}+\beta_{4} d[4]_{g, t}+\varepsilon_{g, t}
$$

where $d_{\text {high }}$ is one (zero) when exposure is high (low) and $d[C]_{g, t}$ is one for group $g$ in period $t$ if going from the initial to the optimal allocation involves cycle $C$ (and it is zero otherwise). The estimation results show that for the simple market $\beta_{0}$ is negative and significant while the cycle dummies are not significantly different 12 For the package market the cycle dummies are also not significantly different and $\beta_{0}$ is positive but not significant. ${ }^{13}$

Result 2 shows it is not the complexity of the optimal trade cycle that drives the difference between the simple and package market. What does? Recall from Section 2 that there are two disadvantages to buying in the simple market. Since houses are substitutes the price paid for a second house typically exceeds the increase in value to the buyer, a loss that can be recouped only if the buyer is able to sell the first house. Second, owning two houses creates a weak bargaining position since the marginal value of the less preferred house is zero. Others may try to exploit this weaker position by waiting until the end of the period before making a low offer.

\footnotetext{
${ }^{12}$ For the simple market the estimates are $\beta_{0}=-0.24(0.11), \beta_{1}=0.15(0.12), \beta_{2}=0.41(0.12), \beta_{3}=0.40(0.28)$, and $\beta_{4}=0.32(0.13)$. We cannot reject the null hypothesis that $\beta_{1}=\beta_{2}=\beta_{3}=\beta_{4}(p=0.33, F$-test $)$.

${ }^{13}$ For the package market the estimates are $\beta_{0}=0.08(0.04), \beta_{1}=0.76(0.04), \beta_{2}=0.81(0.05), \beta_{3}=0.78(0.11)$, and $\beta_{4}=0.71(0.05)$. We cannot reject the null hypothesis that $\beta_{1}=\beta_{2}=\beta_{3}=\beta_{4}(p=0.34, F$-test $)$.
} 


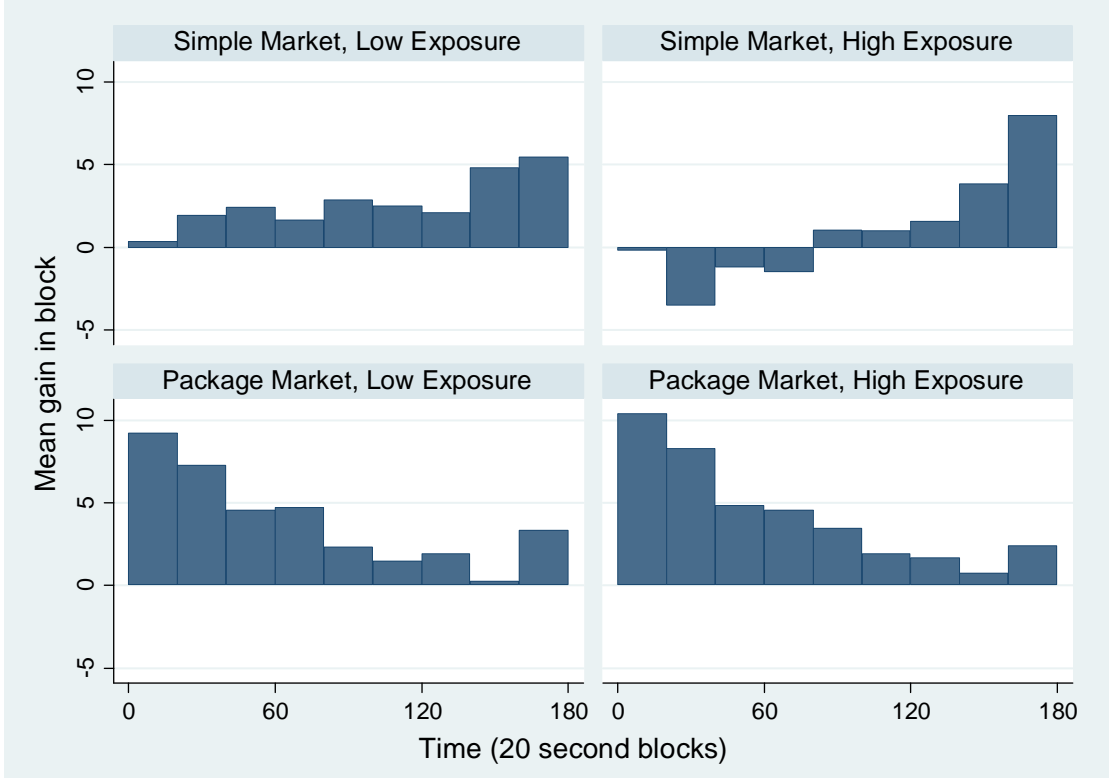

Figure 1: Evolution of realized gains from trade by blocks of 20 seconds. The top two panels pertain to the simple market and the bottom panels to the package market.

Of course, foreseeing both types of problems, the entire group may be hesitant to start trading and be the first to buy ${ }^{14}$ The next result shows that the simple market is indeed prone to such "hold out" problems.

Result 3: In the simple market most gains from trade are realized at the end of the period. In contrast, in the package market they are realized at the start of the period.

Figure 1 shows when gains or losses from trade occurred. The three minute trading period is divided into nine 20 second blocks. The average number of points gained or lost during each block is shown for each of the treatments. Clearly, the simple CDA is subject to a severe hold out problem, which is virtually absent in the package market where most trading occurs in the first half of the period. Note from the top-right panel of Figure 1 that the simple market initially has negative gains from trade when exposure risk is high. In the next section, we investigate in more detail how exposure risk affects the performance of the CDA.

\subsection{Exposure Risk in the Simple Market}

We first rephrase Result 1 to highlight the effect of exposure risk.

\footnotetext{
${ }^{14}$ Note that these concerns do not apply when package orders are used since then no subject owns two houses at any point in time.
} 


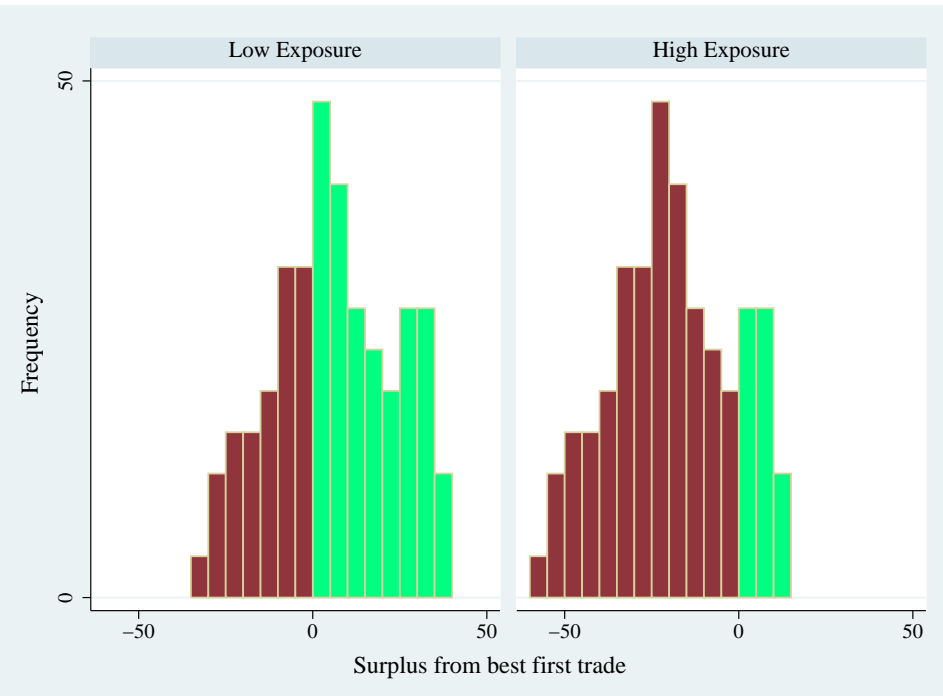

Figure 2: Histograms of best first trades with low exposure (left) and high exposure (right). The dark (light) bars correspond to negative (positive) best first trades. Note that the histogram for the high exposure case is simply shifted 25 to the left.

Result 4: Decreasing the level of exposure raises the gains from trade in the simple market from 20 percent to 55 percent 15 Decreasing the level of exposure does not affect the gains from trade in the package market.16

The difference between the high and low exposure treatments is that in the high exposure treatments all house values are 25 points higher. This means that the potential gains from trade are identical in both treatments but that losses from the first trade are larger in the highexposure treatment. Figure 2 shows the distribution of the gains and losses from the best first trade in the low and high exposure treatments. The best first trade is defined as follows. The surplus from the first trade when agent $i$ buys agent $j$ 's house is $\pi_{i}+\pi_{j}=\max \left(v_{i}^{j}, v_{i}^{i}\right)-v_{j}^{j}-v_{i}^{i}$. The best first trade is the first trade that gives the highest surplus from the set of all possible first trades where $i \neq j$. Figure 2 shows how adding a constant to all values shifts the distribution of best first trades to the left. The consequence is that there are fewer best first trades with a positive surplus, i.e. exposure risk occurs more frequently.

Result 5: In the simple market, when the first trade was not profitable, the probability of no trade and the probability of trade leading to losses both increased significantly. This resulted in low average gains from trade in the simple market.

\footnotetext{
${ }^{15}$ This difference is significant ( $p=0.0015$, Mann-Whitney test).

${ }^{16}$ Gains from trade fall from $89 \%$ to $82 \%$ but this difference is not significant ( $p=0.2482$, Mann-Whitney test).
} 


\begin{tabular}{|c||c|c|c||c|c|c|}
\hline \multicolumn{1}{|c||}{} & \multicolumn{3}{c||}{ No Trade } & \multicolumn{3}{c|}{ Trade Leading to Loss } \\
\hline \hline & Pooled & High Exposure & Low Exposure & Pooled & High Exposure & Low Exposure \\
\hline 1st trade loss $(\beta)$ & $1.508^{* * *}$ & $0.903^{* *}$ & $2.018^{* * *}$ & $0.988^{* * *}$ & $1.289^{* *}$ & $1.030^{* * *}$ \\
\hline & $(0.225)$ & $(0.329)$ & $(0.324)$ & $(0.187)$ & $(0.447)$ & $(0.254)$ \\
\hline constant $(\alpha)$ & $-1.821^{* * *}$ & $-1.393^{* * *}$ & $-2.009^{* * *}$ & $-1.548^{* * *}$ & $-1.889^{* * *}$ & $-1.501^{* * *}$ \\
\hline & $(0.208)$ & $(0.318)$ & $(0.288)$ & $(0.163)$ & $(0.433)$ & $(0.200)$ \\
\hline \# Groups & 24 & 12 & 12 & 24 & 12 & 12 \\
\hline \# Obs & 360 & 180 & 180 & 360 & 180 & 180 \\
\hline
\end{tabular}

Table 5: Probit estimations of the probability of no trade and the probability of trade leading to a loss in the simple market using negative best first trade as an explanatory variable. Standard errors are in parentheses; ${ }^{* * *}$ indicates $p<0.001,{ }^{* *}$ indicates $p<0.01$, and ${ }^{*}$ indicates $p<0.05$.

For the treatments that employed the simple market mechanism, the frequency of no trade is $36.8 \%$ when there is no profitable first trade versus $2.9 \%$ when a profitable first trade exists. Similarly, the frequency of trade leading to losses is $28.8 \%$ when the best first trade is negative and $6.1 \%$ otherwise. These effects can be substantiated using Probit models:

$$
\begin{array}{r}
\operatorname{Prob}(\text { No Trade } \mid x)=\Phi\left(\alpha+x \beta+v_{g}\right) \\
\operatorname{Prob}(\operatorname{Loss} \mid x)=\Phi\left(\alpha+x \beta+v_{g}\right)
\end{array}
$$

There is one observation per group per round. If the best available first trade involves a loss, $x=1$ and if not $x=0$. The term $v_{g}$ is a group-specific random effect. Table 5 shows that when the best available first trade involves a loss, there is a significantly higher probability of no trade and of the group making a loss. The losses typically resulted from failing to make additional trades after a negative first trade.

Figure 3 shows the initial and final realized gains from trade disaggregated by treatment. There is one point on the plot for each group in each period. The value of an allocation is calculated as follows:

$$
s(\Omega)=\sum_{i=1}^{4} \max \left(v_{i}^{1} \omega_{i}^{1}, \ldots, v_{i}^{4} \omega_{i}^{4}\right)
$$

As before, the allocation of houses is represented by $\Omega=\left\{\omega_{1}, \ldots, \omega_{N}\right\}$. The vector $\omega_{i}$ indicates which houses agent $i$ holds, $\omega_{i}^{h}$ is one if the agent holds house $h$ and zero otherwise. Agent $i$ 's value for house $h$ is $v_{i}^{h}$. The unrealized gains values were calculated as follows:

$$
\begin{aligned}
& \text { Initial Loss }=s\left(\Omega_{0}\right)-s\left(\Omega^{*}\right) \\
& \text { Final Loss }=s\left(\Omega_{f}\right)-s\left(\Omega^{*}\right)
\end{aligned}
$$

where $\Omega_{0}$ is the initial allocation of houses to agents, $\Omega^{*}$ is the optimal allocation, and $\Omega_{f}$ is the allocation that was obtained at the end of the period. This absolute measure of loss is 


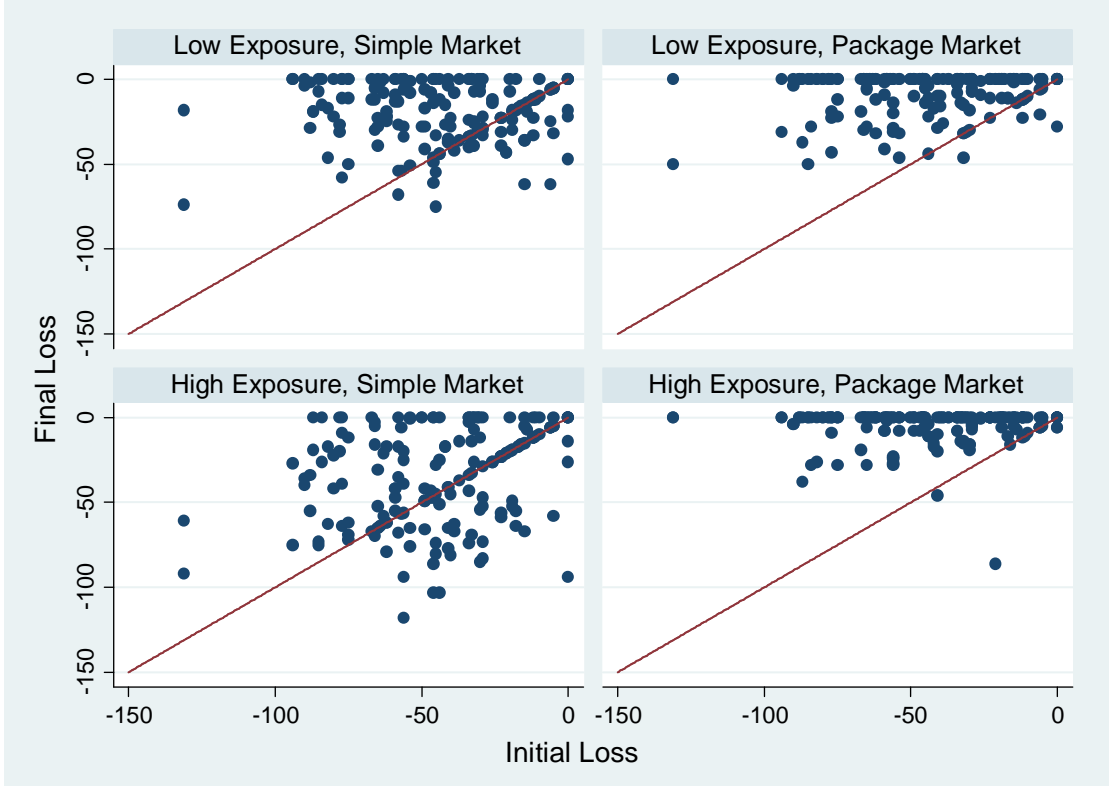

Figure 3: Realized and unrealized gains from trade in the simple market (left panels) and package market (right panels). Points on the 45-degree line correspond to instances of no trade and points below (above) the 45-degree line to instances of negative (positive) overall gains from trade.

used instead of a proportional one to make values from the high and low exposure treatments comparable. The vertical position of points on the graph indicate how much of the gains from trade were realized. A final loss of zero means all available gains from trade were realized. In all treatments, the optimal allocation was achieved by some groups in some periods. In periods where no trade occurred, points lie on the 45-degree line. It can be seen that this was common in the simple market and rare in the package market. Points below the 45-degree line indicate that there was trade but that the final allocation left the group worse off than they had started. Again, this occurred frequently in the simple market treatments and rarely in the package market.

The risk of exposure when buying did not go unnoticed by the subjects. The next result demonstrates that they mostly tried to sell their house rather than buying a second one, and that those who bought were typically worse off.

Result 6: In the simple market, sell orders were submitted more frequently than buy orders and those who sold first made significantly more than those who bought first. In the package market, most submitted orders were package orders.

The final three columns of Table 3 shows the percentage of buy, sell, and package orders disaggregated by treatment. In the simple market, it was not possible to submit package orders 


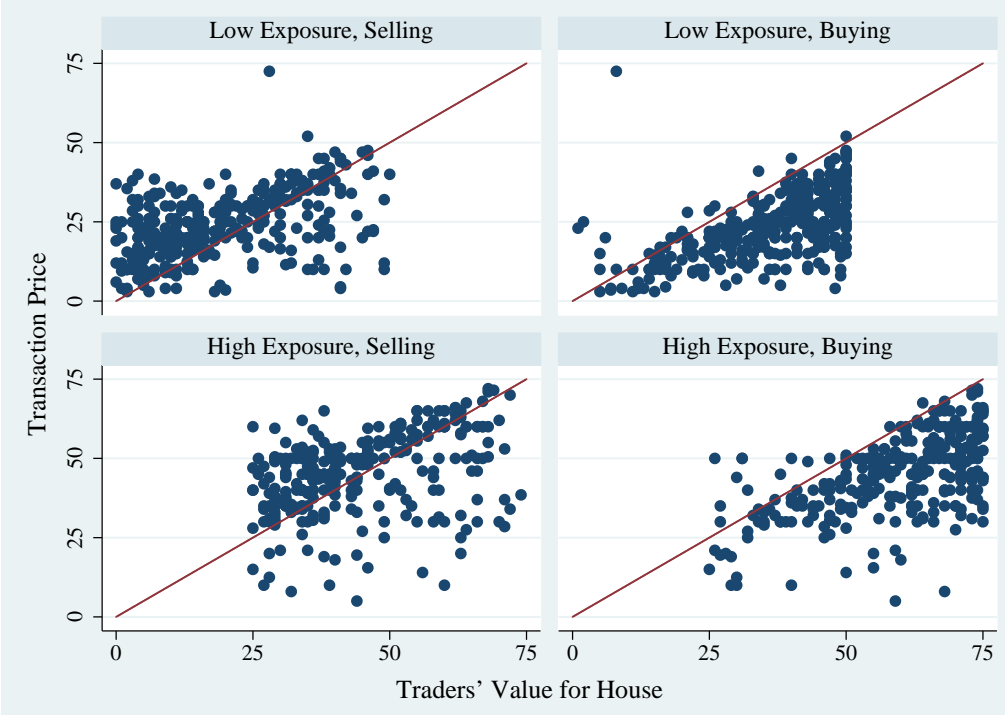

Figur 4: Scatter plot of transaction prices versus house values in the simple market with low exposure (top panels) and high exposure (bottom panels). The left panels show sell prices and the right panels show buy prices.

whereas in the package market, all types of order were admissible. In the simple market with high and low exposure approximately two-thirds of the orders were offers to sell. This indicates that subjects were often unwilling to take on two houses. Indeed, subjects typically made more when they sold first (15.0 points and 13.0 points in the low and high exposure treatments respectively) than when they bought first (5.6 points and -4.8 points in the low and high exposure treatments respectively) $!^{17}$ In the package market, a large majority of subjects used package orders.

Figure 4 shows a scatter plot of transaction prices versus house values. The right panels indicate that subjects almost never paid more than their value for the house, which is to be expected if subjects act rationally. The sell prices shown in the left panels were frequently below value, which is not necessarily irrational. For example, when more than one house is held only the value of the best house counts, so selling one below value can be rational. Indeed, in 73 percent of the cases where the house was sold below value, the seller had two houses. In contrast, in only 28 percent of the cases where the house was sold above value did the seller have two houses 18

\footnotetext{
${ }^{17}$ The difference in gain between those who bought first and those who sold first is significant in the low and high exposure treatments ( $p=0.0001$ and $p<0.0001$ respectively, Mann-Whitney tests).

${ }^{18}$ The difference is significant $(p<0.001$, Pearson's chi-squared test).
} 

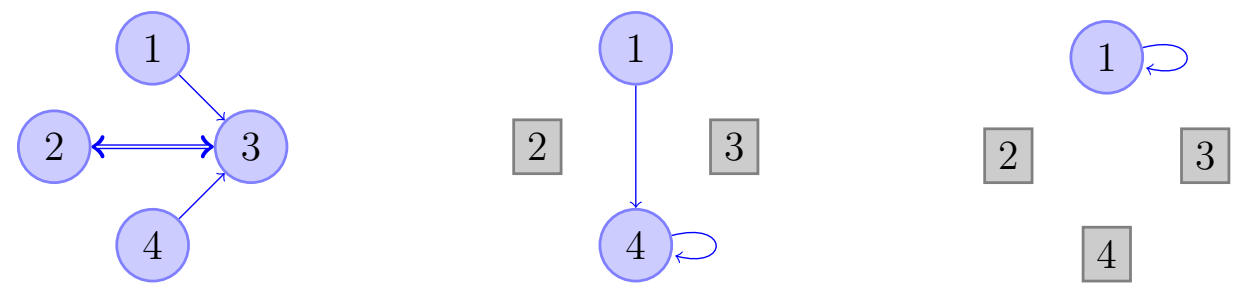

Figure 5: Illustration of the top-trading-cycles procedure based on the example in Table 1. In the first step houses $B$ and $C$ belonging to homeowners 2 and 3 are removed (left panel). In the next step, house $D$ belong to homeowner 4 is removed (middle panel). In the final step, house $A$ belonging to homeowner 1 is removed (right panel).

\subsection{Comparison to Top-Trading-Cycles Procedure}

The top-trading-cycles procedure reallocates houses without cash transfers, see e.g. Shapley and Scarf (1974). House owners simply point to the house they prefer best among those available. The mechanism proceeds in several steps, where in each step the houses (and owners) that form cycles are removed. Figure 5 illustrates the procedure using the example of Table 1. Since subjects 2 and 3 point to each other's house they are removed in step one. In step two, both remaining subjects point to subject 4's house, which is removed. In the final step the house belonging to subject 1 is removed. Note that the top-trading-cycles procedure does not result in the efficient allocation indicated by the starred values in Table 1.

For each of the groups and each of the periods, the allocation that would be produced by running the algorithm was found. The proportion of realized gains from running the algorithm is 68 percent. This is considerably less than the proportion of gains actually realized in the package market but considerably more than was realized in the simple market.

Result 7: The gains from trade realized in the package market are significantly higher than those that could have been achieved using the top-trading-cycles procedure 19 The gains from trade realized in the simple market are significantly less than those that could have been achieved using the top-trading-cycles procedure ${ }^{20}$

It is striking that the simple top-trading-cycles procedure outperforms the CDA in both the low and high-exposure treatments. Since the procedure does not involve any money it easily results in inefficient allocations, e.g. if one of the homeowners prefers her own house when this

\footnotetext{
${ }^{19} \mathrm{~A}$ simple $t$-test rejects the null hypothesis that the realized gains from trade in the package market are equal to $68 \%$, for both the low $(p=0.009)$ and high $(p<0.0001)$ exposure treatments.

${ }^{20} \mathrm{~A}$ simple $t$-test rejects the null hypothesis that the realized gains from trade in the simple market are equal to $68 \%$, for both the low $(p=0.02)$ and high $(p<0.0001)$ exposure treatments.
} 
is not part of the optimal allocation. Such inefficiencies do not occur when money is introduced as in the package format we propose.

\section{Extensions and Conclusions}

The experiments reported in the paper were deliberately designed to be simple. Items were substititutes, there were well-defined property rights and no transaction costs. In addition, in half the treatments there was perfect information. These are conditions where one might expect the Coase theorem to hold, i.e. "bargaining will to lead to an efficient outcome no matter how property rights are allocated." The results show that in a standard double auction market only a small fraction of the total gains from trade are realized, both with complete and incomplete information. This poor performance is due to the exposure risk that arises when going from the initial allocation to the optimal one requires someone to temporally make a loss. The solution presented in this paper is a simple package market.

There are several paths future work could explore. One direction is running laboratory experiments investigating how different market institutions cope with the exposure problem in more complex environments. Factors such as the group size and time allowed for trading could be varied. Cheap talk communication could be introduced. Dynamic factors such as the following could be studied: a cost to delaying trading, agents arriving over time, agents' induced preferences could change over time (representing, for example, life cycle events like having children), and uncertain or endogenous period length. Another direction for future work is modeling and predicting behavior, and developing a more general theoretical account of behavior.

The package market we propose shares some features with contingent contracting, which can also be used to reduce exposure risk ${ }^{21}$ For example, Collins and Isaac (2011) find that the holdout problem in land assembly can be mitigated using contingent contracts. In some countries, real estate sale contracts can be contingent on the buyer selling their home, which removes the risk of being left with two houses. There are important differences with the proposed package market, however. First, in the context of the real-estate example, contingent contracts typically restrict the seller from selling to another buyer, in a sense shifting the exposure from the buyer to the seller, a feature that is not present in the package market.

\footnotetext{
${ }^{21}$ Contingent contracts are used in a range of settings and can take various forms. Payments can be contingent on a natural event occurring, for instance flood insurance, or payments can be contingent on prices, for instance employment contracts with a wage indexed on the rate of inflation.
} 
Second, the package market provides for a decentralized solution in that orders in the package market do not have to identify a counter party, e.g. an offer to exchange house $A$ for house $B$ does not specify who will take house $A$. The offer could be part of a transaction cycle of length three or more, in which case it is not the owner of house $B$ that takes house $A$. Importantly, when submitting orders, homeowners do not have to worry about which type of transaction cycle will result. The package market provides a decentralized clearing mechanism, which could reduce search and contracting costs.

The package format proposed in this paper is a simple extension of the continuous double auction. As such it has the promise to be applicable in a variety of circumstances, including markets for expensive durables, financial markets, trading of basketball or soccer players, airport landing slots, emission permits (see, e.g., Cason, 1995), etc. By allowing for orders that include both a sell and a buy plus some amount of cash, the package market eliminates exposure risk and produces efficient outcomes in situations where the continuous double auction and the top-trading-cycles procedure fail. 


\section{References}

Balakrishnan, H. (2007) "Techniques for Reallocating Airport Resources During Adverse Weather," in Proceedings of the 46th IEEE Conference on Decision and Control, 29492956.

Bossaerts, P., Fine, L., and J. O. Ledyard (2002) "Inducing Liquidity in Thin Financial Markets Through Combined-Value Trading Mechanisms," European Economic Review, 46, 16711695.

Brunner, C., Goeree, J. K., Holt, C., and J. O. Ledyard (2010) "An Experimental Test of Flexible Combinatorial Spectrum Auction Formats," American Economic Journal: Microeconomics, 2, 39-57.

Cason, T. (1995) "An Experimental Investigation of the Seller Incentives in EPAs Emission Trading Auction," American Economic Review, 85, 905-922.

Collins, S.M. and M. R. Isaac (2011) "Holdout: Existence, Information, and Contingent Contracting," working paper, Florida State University.

Friedman, D. (2010) "Preferences, Beliefs and Equilibrium: What Have Experiments Taught Us?" Journal of Economic Behavior and Organization, 73, 29-33.

Kwasnica, T. Ledyard, J. O., Porter, D. and DeMartini, C. (2005) "A New and Improved Design for Multiobject Iterative Auctions," Management Science, 51, 419-434.

Lubin, B., Juda, A., Cavallo, R., Lahaie, S., Shneidman, J. and D. C. Parkes (2008) "ICE: An Expressive Iterative Combinatorial Exchange," Journal of Artificial Intelligence Research, 33, 33-77.

Milgrom, P. (2007) "Package Auctions and Exchanges," Econometrica, 75, 935-965.

Milgrom, P. (2009) "Assignment Messages and Exchanges," American Economic Journal: Microeconomics, 1, 95-113.

Shapley, L. and H. Scarf (1974) "On Cores and Indivisibility," Journal of Mathematical Economics, 1, 23-37.

Shapley, L. and M. Shubik (1971) "The Assignment Game I: The Core," International Journal of Game Theory, 1, 111-130.

Smith, V. (1962) "An Experimental Study of Competitive Market Behavior," Journal of Political Economy, 70, 111-137.

Smith, V. (1982) "Microeconomic Systems as an Experimental Science," American Economic Review, 72, 923-955.

Smith, V. (2010) "Theory and Experiment: What Are the Questions?" Journal of Economic Behavior and Organization, 73, 3-15.

Van Boening, M. V. and N. T. Wilcox (1996) "Avoidable Cost: Ride a Bouble Auction Roller Coaster," American Economic Review, 86, 461-477. 


\section{A. Appendix: eZtrade Software}

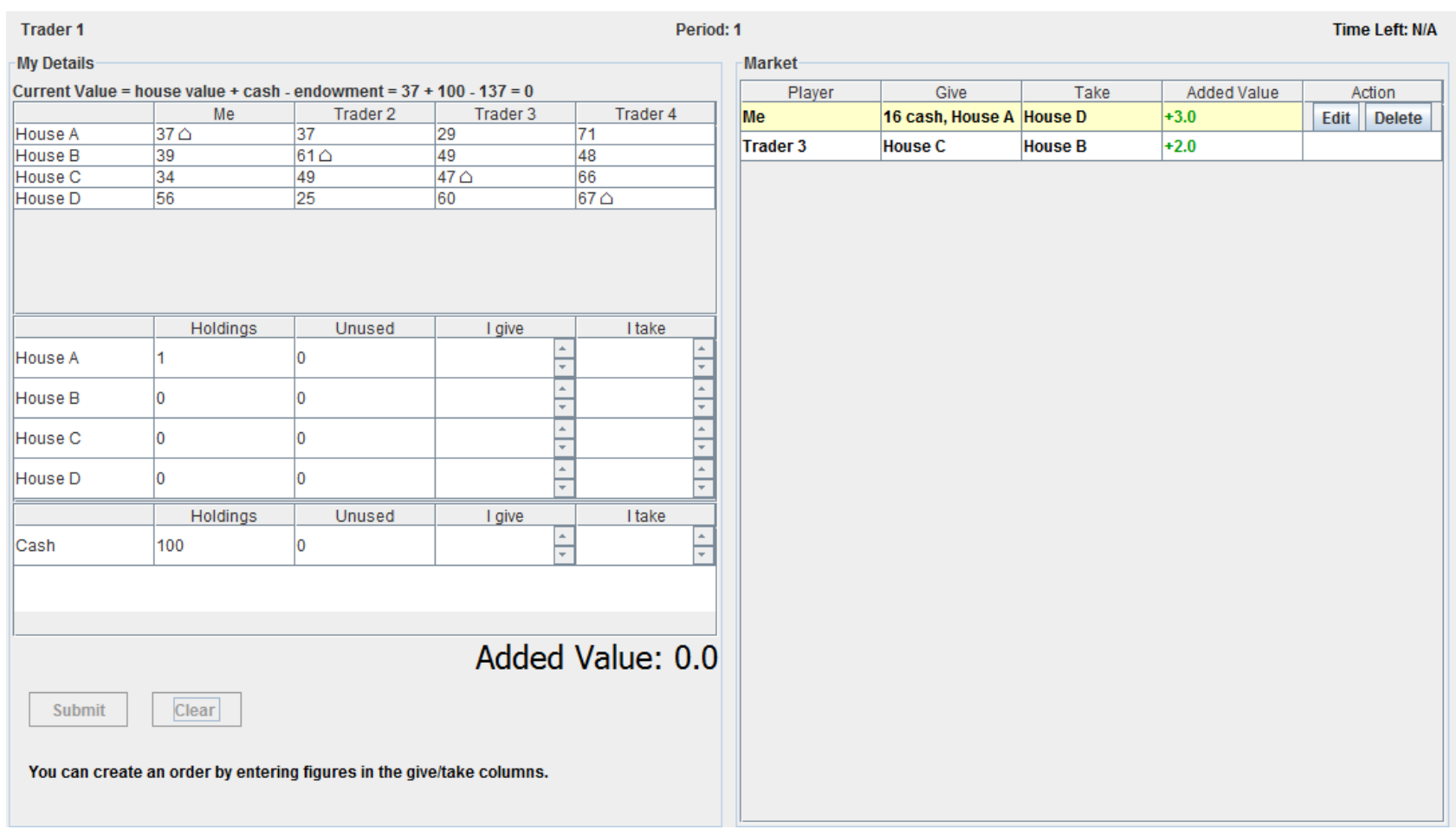

Figure A1: Screenshot of the experimental software. This screenshot is from the treatment with the package market, high exposure, and complete information. The screen is from point of view of trader 1 . The table on the top left of the screen shows each of the players' values for the houses and how the houses are currently allocated. The lower left table is used to construct orders. This is done by entering figures in the "I give" and "I take" columns. As figures are entered, the "Added Value" figure automatically updates to show the player how their earnings will change if the order transacts. The table on the right hand side shows the orders that have been submitted. There are currently two active orders. Trader 1 (labeled "Me") is offering to give 16 cash and house A in exchange for house D. Trader 3 is offering to swap house $\mathrm{C}$ for house B. There have not been any transactions yet. 